Wilfrid Laurier University

Scholars Commons @ Laurier

Physics and Computer Science Faculty

Publications

Physics and Computer Science

2004

\title{
Ion-Exchanged Waveguides in Glass Doped with PbS Quantum Dots
}

Jason M. Auxier

University of Arizona

Michael M. Morrell

Unviersity of Arizona

Brian R. West

Wilfrid Laurier University, bwest@wlu.ca

Seppo Honkanen

University of Arizona

Axel Shülzgen

University of Arizona

See next page for additional authors

Follow this and additional works at: https://scholars.wlu.ca/phys_faculty

\section{Recommended Citation}

Auxier, Jason M.; Morrell, Michael M.; West, Brian R.; Honkanen, Seppo; Shülzgen, Axel; Peyghambarian, Nassar; Sen, Sabyasachi; and Borrelli, Nicholas F., "Ion-Exchanged Waveguides in Glass Doped with PbS Quantum Dots" (2004). Physics and Computer Science Faculty Publications. 85.

https://scholars.wlu.ca/phys_faculty/85

This Article is brought to you for free and open access by the Physics and Computer Science at Scholars Commons @ Laurier. It has been accepted for inclusion in Physics and Computer Science Faculty Publications by an authorized administrator of Scholars Commons @ Laurier. For more information, please contact scholarscommons@wlu.ca. 


\section{Authors}

Jason M. Auxier, Michael M. Morrell, Brian R. West, Seppo Honkanen, Axel Shülzgen, Nassar

Peyghambarian, Sabyasachi Sen, and Nicholas F. Borrelli 


\title{
lon-exchanged waveguides in glass doped with $\mathrm{PbS}$ quantum dots
}

\author{
Jason M. Auxier, ${ }^{\text {a) }}$ Michael M. Morrell, Brian R. West, Seppo Honkanen, \\ Axel Schülzgen, and Nasser Peyghambarian \\ Optical Sciences Center, University of Arizona, Tucson, Arizona 87521-0094

\begin{abstract}
Sabyasachi Sen and Nicholas F. Borrelli
Glass Research Group, Corning, Inc., Research and Development Center, Sullivan Park, Corning, New York 14831
\end{abstract}

(Received 20 July 2004; accepted 19 October 2004)

\begin{abstract}
The lowest-loss ( $\leqslant 1 \mathrm{~dB} / \mathrm{cm}$ ) ion-exchanged waveguides in glass doped with $\mathrm{PbS}$ quantum dots are presented. Near-field mode profile and refractive index profile using the refracted near-field technique were measured for these waveguides. We demonstrate that the optical properties of this glass remain unchanged during the ion-exchange process. (C) 2004 American Institute of Physics. [DOI: $10.1063 / 1.1839284]$
\end{abstract}

Semiconductor-doped glasses have several advantages over their epitaxially grown counterparts. Principally, doped glasses are less expensive to fabricate than structures grown through molecular beam epitaxy. Suitable thermal treatment of a glass containing the chemical components of a semiconductor can precipitate semiconductor quantum dots (QDs) with narrow-size distributions, few substitutional defects, and few dangling bonds. ${ }^{1}$ The three-dimensional (3D) quantum confinement of the semiconductor QDs allows us to tailor the optical absorption. ${ }^{2}$ These properties make QD-doped glass an attractive candidate for the production of photonic devices.

The PbS QDs studied here have radii $(2-5 \mathrm{~nm})$ smaller than the bulk exciton Bohr radius $(18 \mathrm{~nm})$, which places them within the strong 3D-confinement limit. The small bulk band gap energy $(0.4 \mathrm{eV}$ at $300 \mathrm{~K})$ allows us to tune the ground excited state transition throughout the near infrared. Figure 1 shows the room temperature absorption spectra of $\mathrm{PbS}$ QD-doped glasses with different dot radii. The QD radii $R$ quoted in Fig. 1 are calculated using a hyperbolic band model: ${ }^{3,4}$

$$
\left(\hbar \omega_{1 s}\right)^{2}=\left(\frac{h c}{\lambda_{1 s}}\right)^{2}=E_{g}^{2}+\left(\frac{2 \hbar^{2} E_{g}}{m^{*}}\right)\left(\frac{\pi}{R}\right)^{2}
$$

where we used the room temperature $(T=300 \mathrm{~K})$ band gap energy of $E_{g}=0.41 \mathrm{eV}$ and effective mass of $m^{*}=0.12 m_{0}$ for $\mathrm{PbS}{ }^{4}$

The nonlinear optical properties of PbS QD-doped glasses have been studied recently for mode-locking ${ }^{5,6}$ and gain $^{7,8}$ applications; however, all of these studies have been performed in bulk glasses. Waveguides in semiconductordoped glasses have been produced for integrated photonic devices. ${ }^{9,10}$ This letter demonstrates much lower-loss waveguides in a QD-doped glass using a $\mathrm{K}^{+}-\mathrm{Na}^{+}$ionexchange process.

Ion exchange is used to produce commercially available planar-lightwave circuits (PLCs). ${ }^{11}$ These PLCs are produced using a field-assisted burial process that produces waveguides with extremely low loss, birefringence, and polarization dependent loss. ${ }^{11}$

\footnotetext{
${ }^{a)}$ Electronic mail: auxier@optics.arizona.edu
}

Thermal diffusion of ions is the physical mechanism for the ion-exchange process. A potassium nitrate molten salt supplies potassium replacement ions for sodium ions in the glass. This ion exchange produces an index change by altering the local glass density and mean polarizability. ${ }^{11,12}$ The Lorentz-Lorenz formula describes the polarizability.

$\mathrm{Ag}^{+}-\mathrm{Na}^{+}$ion exchange was not used here due to the reduction of silver in the glass. This silver nanoparticle formation was confirmed by optical absorption spectroscopy and scanning electron microscopy. $\mathrm{K}^{+}-\mathrm{Na}^{+}$ion exchange requires more time due to the lower self-diffusion coefficient of potassium ions.

In preparation for the ion-exchange process, the glass sample was surface polished, cleaned, and coated with titanium. The titanium film serves as the ion-exchange mask after lithographic processing. The titanium was coated with photoresist, which was patterned, developed, and cured. The developed photoresist served as a mask for titanium etching. After etching and photoresist removal, the sample was ready for ion exchange [see Fig. 2(a)]. After ion exchange, the titanium was removed and the sample was cut and polished for device characterization [see Fig. 2(b)]. Figure 3 shows

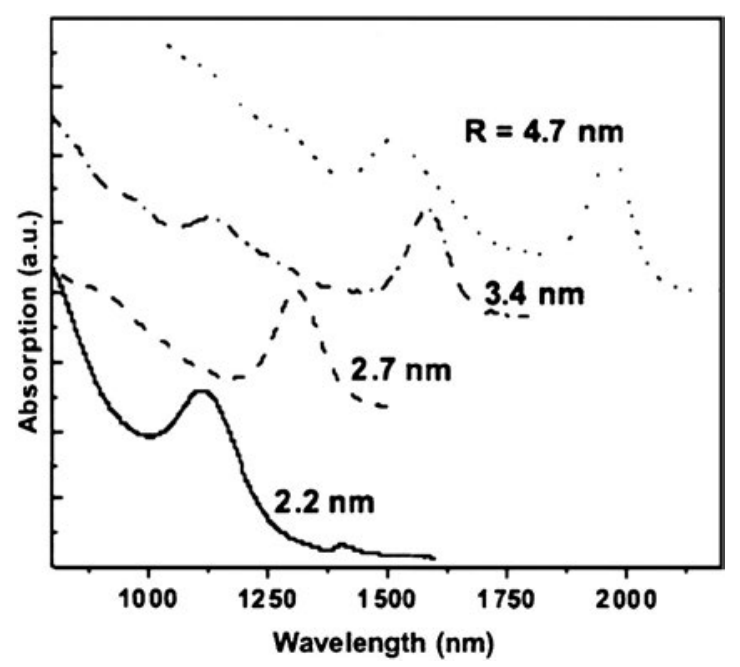

FIG. 1. Room-temperature absorption spectra of PbS QD-doped glasses with mean QD radii $R$. The solid line $(R=2.2 \mathrm{~nm})$ represents the sample in which the ion-exchange waveguides have been fabricated. The small absorption feature around $1400 \mathrm{~nm}$ is also present in the host glass without QDs. 
(a)
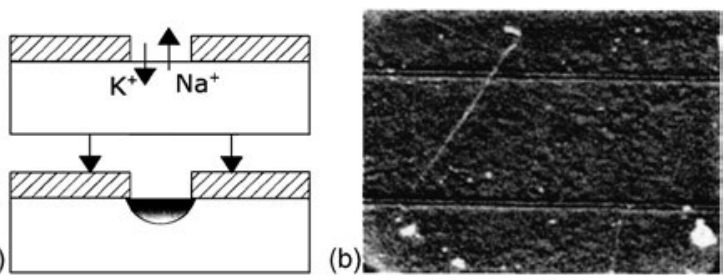

FIG. 2. (a) Ion-exchange process and (b) a phase-contrast micrograph of two $\mathrm{PbS}$ QD-doped channel waveguides after $\mathrm{K}^{+}-\mathrm{Na}^{+}$ion exchange (380 C, 234 h).

the mode profile of one of these channel (surface) waveguides.

To evaluate the quality of these channel waveguides we analyzed the losses using the fiber-waveguide-objective method. We compared the loss when the waveguide was fiber-coupled at both facets to the loss when the waveguide was fiber-coupled at the input only and the light was collected by a microscope objective at the output. Table I summarizes losses for several of these QD-doped waveguides. We measured a low guide loss of $<0.5 \mathrm{~dB} / \mathrm{cm}$ for all these surface waveguides.

We measured the index profile using the refracted nearfield (RNF) technique, which was first used to profile optical fibers ${ }^{13}$ and later adapted to measuring planar waveguides in glass. ${ }^{14}$ This technique relies on the index variation being perpendicular to the optical axis. Using the known index of a reference material $n_{\text {ref }}$ and applying Snell's law, the waveguide's refractive index profile $n(x, y)$ can be expressed as $^{13}$

$$
n^{2}(x, y)=\sin ^{2} \theta_{1}+n_{\text {ref }}^{2}-\sin ^{2} \theta_{2},
$$

where $\theta_{1}$ and $\theta_{2}$ are incident and exit angles. For a focused incident beam and small index variations, the power incident
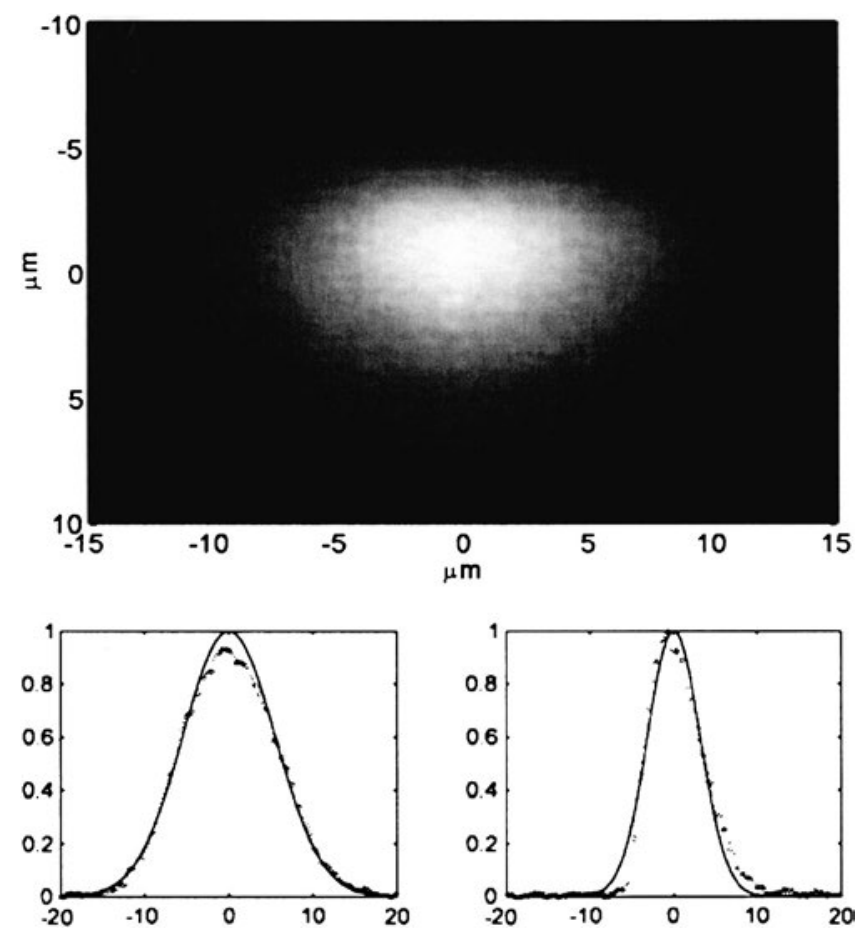

FIG. 3. (a) Near-field image of the mode profile along with its (b) horizontal (20 $\mu \mathrm{m} e^{-1}$ width) and (c) vertical (12 $\mu \mathrm{m} e^{-1}$ width) cross sections at $1550 \mathrm{~nm}$ from a channel waveguide ( $3.5 \mu \mathrm{m}$ mask opening). The mode was collected using a 0.4 n.a. objective and imaged onto a NIR camera. The mode profile is asymmetric since these are surface waveguides.
TABLE I. Propagation, guide, coupling, and ideal coupling losses for $\mathrm{K}^{+}-\mathrm{Na}^{+}$ion-exchanged waveguides.

\begin{tabular}{ccccc}
\hline \hline $\begin{array}{c}\text { Mask width } \\
(\mu \mathrm{m})\end{array}$ & $\begin{array}{c}\text { Propagation loss } \\
(\mathrm{dB} / \mathrm{cm})\end{array}$ & $\begin{array}{c}\text { Guide loss }^{\mathrm{b}} \\
(\mathrm{dB} / \mathrm{cm})\end{array}$ & $\begin{array}{c}\text { Coupling loss } \\
(\mathrm{dB} / \mathrm{cm})\end{array}$ & $\begin{array}{c}\text { Ideal loss }^{\mathrm{c}} \\
(\mathrm{dB})\end{array}$ \\
\hline 5 & 0.84 & 0.47 & $1.92 \pm 0.03 \mathrm{~d}$ & 1.26 \\
4 & 0.81 & 0.44 & $2.16 \pm 0.04$ & 1.18 \\
3.5 & 0.74 & 0.37 & $2.41 \pm 0.16$ & 0.97 \\
3 & 0.70 & 0.33 & $4.51 \pm 0.10$ & 1.30 \\
2 & 0.70 & 0.33 & $2.59 \pm 0.36$ & 1.15 \\
\hline \hline
\end{tabular}

${ }^{\mathrm{a}}$ All losses were measured at $1550 \mathrm{~nm}$.

${ }^{\mathrm{b}}$ The QD absorption of $0.37 \mathrm{~dB} / \mathrm{cm}$ was removed.

${ }^{\mathrm{c}}$ The ideal fiber-waveguide coupling losses were calculated from the overlap integrals between the waveguide and SMF-28 mode profiles.

${ }^{\mathrm{d}}$ The measurement error was estimated to be the difference between fiberwaveguide-fiber configuration measurements when input-output facets were swapped.

on the detector is proportional to the refractive index profile (with a dc offset). ${ }^{13}$ Figure 4 shows the index profile of a waveguide we measured using the RNF technique.

The mask opening is much smaller than the resulting waveguide. The long exchange time allows the potassium to enter the glass and diffuse along the surface, resulting in a distributed and elliptical index profile; however, the region of highest index change is well confined, which keeps the waveguide single-mode.

These waveguides not only provide optical confinement, they are semi-homogeneously doped with $\mathrm{PbS}$ QDs. Figure 5 shows luminescence from samples with and without ion exchange and from an ion-exchanged waveguide. There is no noticeable difference between these spectra, which demonstrates that the optical properties of the quantum dots remain unchanged through the ion-exchange process. Thus, we indeed have QD-doped waveguides.

In Fig. 5, the luminescence spectrum is broader than the absorption peak. This is due to trapped surface states in these QDs. For the QD sample shown in Fig. 1 with the $1 \mathrm{~s}$ transition around $1300 \mathrm{~nm}$, we measured a binding energy for these trapped states of $30 \mathrm{meV}$. Additionally, these trapped states produce luminescence with high quantum efficiency ( $\sim 8 \%)$, have a $10 \mu$ s lifetime, and show a typical saturation behavior with a saturation intensity of $40 \mathrm{~mW}$ (at $1064 \mathrm{~nm}$ ). This is in contrast with the direct recombination lifetime,

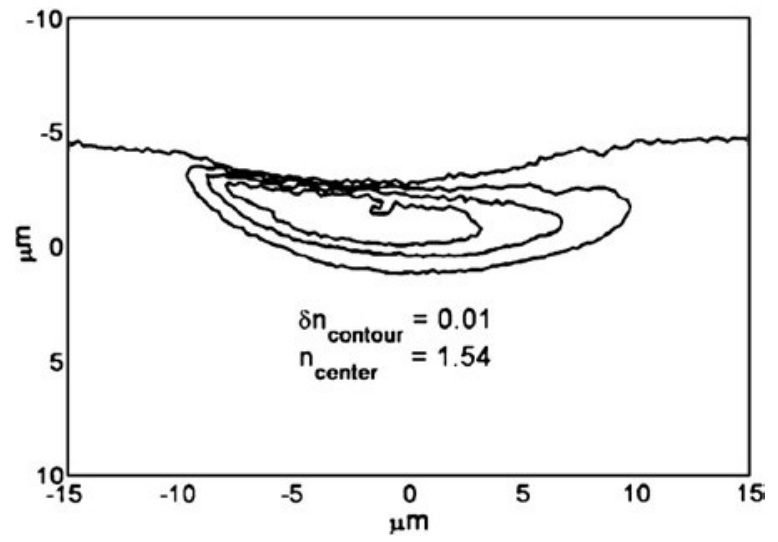

FIG. 4. Index profile of a channel (PbS QD-doped) waveguide measured by the RNF technique at $1550 \mathrm{~nm}$. With $\mathrm{K}^{+}$exchange, one expects a ridge at the surface; however, the dip here is due to the harsh etching process we used to completely remove the titanium mask. The width of the index profile increased with increasing mask opening. 


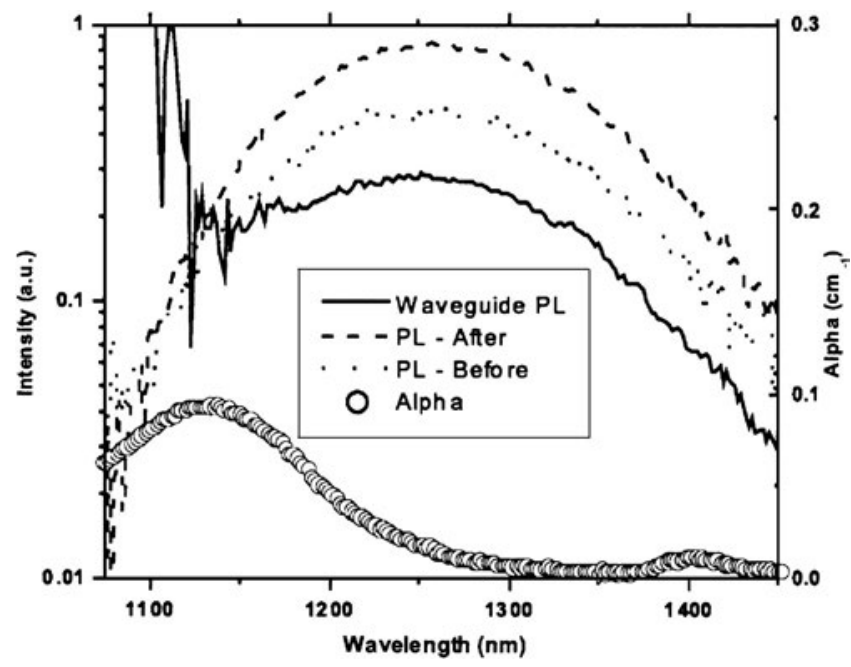

FIG. 5. Luminescence from PbS QD-doped waveguides (solid) and in this glass before (dotted) and after (dashed) ion exchange along with the QD absorption (open circles). The noise in waveguide spectrum around $1100 \mathrm{~nm}$ is due to scattered pump light.

which is in the picosecond regime with a Stokes shift of $25 \mathrm{meV}$.

In conclusion, we fabricated the lowest-loss waveguides in a QD-doped glass with narrow QD size distribution. This is demonstrated through loss measurements and the confirmation that the optical properties of the QDs are preserved through the exchange process. The production of these sur- face waveguides provides the foundation for producing integrated-optical circuits in QD-doped glass.

The authors would like to thank Corning, Inc. for supplying the glass and Kim Winick and Guangyu Li at the University of Michigan for RNF measurements. Support from TRIF (State of Arizona Photonics Initiative) and COEDIP is appreciated.

${ }^{1}$ N. F. Borrelli and D. W. Smith, J. Non-Cryst. Solids 180, 25 (1994).

${ }^{2}$ A. L. Fros and A. L. Fros, Sov. Phys. Semicond. 16, 772 (1982).

${ }^{3}$ Y. Wang, A. Suma, W. Mahler, and R. Kasowski, J. Chem. Phys. 87, 7315 (1987).

${ }^{4}$ I. Kang and F. W. Wise, J. Opt. Soc. Am. B 14, 1632 (1997).

${ }^{5}$ K. Wundke, S. Pötting, J. M. Auxier, A. Schülzgen, N. Peyghambarian, and N. F. Borrelli, Appl. Phys. Lett. 76, 10 (2000).

${ }^{6}$ J. F. Philipps, T. Topfer, H. Ebendorff-Heidepriem, D. Ehrt, R. Sauberbrey, and N. F. Borrelli, Appl. Phys. B: Lasers Opt. B72, 175 (2001).

${ }^{7}$ K. Wundke, J. M. Auxier, A. Schülzgen, N. Peyghambarian, and N. F. Borrelli, Appl. Phys. Lett. 75, 3060 (2001).

${ }^{8}$ J. M. Auxier, K. Wundke, A. Schülzgen, N. Peyghambarian, and N. F. Borrelli, CLEO 2000, Technical Digest TOPS 39, 385 (2000).

${ }^{9}$ T. J. Cullen, C. N. Ironside, C. T. Seaton, and G. I. Stegeman, Appl. Phys. Lett. 49, 1403 (1986).

${ }^{10}$ P. T. Guerreiro, S. G. Lee, A. S. Rodrigues, Y. Z. Hu, E. M. Wright, S. I. Najafi, J. Mackenzie, and N. Peyghambarian, Opt. Lett. 21, 659 (1996).

${ }^{11}$ E. S. I. Najafi, Introduction to Glass Integrated Optics (Artech House, Boston, MA, 1992).

${ }^{12}$ N. F. Borrelli, Microoptics Technology Fabrication and Applications of Lens Arrays and Devices (Dekker, New York, 1999).

${ }^{13}$ K. I. White, Opt. Quantum Electron. 11, 185 (1979).

${ }^{14}$ R. Göring and M. Rothhardt, J. Opt. Commun. 7, 82 (1986). 